\title{
Environmental concern, evidence and global health
}

This issue addresses the close connections between the health of individuals and the health and flourishing of the planet, and our responsibility to steward the resources we've been given. In our first guest editorial, James Hospedales offers a plea to carefully look at the evidence on the rising global health problems generated from the human neglect of maintaining the delicate balance in nature, and our God-directed responsibility to maintain that balance.

Stewardship of the earth also includes knowledge stewardship. Professors Rebecca Meyer and Jason Paltzer introduce a nascent research collaborative to serve Christian organizations by helping them measure and evaluate the results of their work in health and development - to design research and share results. The editors endorse this project which would serve an important need for FBOs to produce the evidence needed for partners, donors, and the international development community. Jason Paltzer and Keyanna Taylor's crosssectional study in this issue supports the need for such a research collaborative initiative.

The COVID-19 pandemic has led to new-found opportunities to measure and evaluate the results of faithbased work. Emily Hirata, Michael Peach, and Sharon Tobing present a case study showing the way Adventist Development and Relief Agency has met the humanitarian needs during the pandemic, highlighting the unique advantage of well-connected FBOs.

James Pender offers an insightful commentary on the work, often-divided, between heath, social development and environmental concerns, and uses his work with The Leprosy Mission as an example of the need to unify these objectives.

Health-related work as cross-cultural Christian mission has evolved over the years. Several authors from the Asia-Pacific region present an integral paradigm of service in academia, government, or research, often in secular organizations, to build health and missional capacity in strategic areas.

July 2021. Christian Journal for Global Health 8(1)
The pandemic has strained not only health services, but church gatherings, which serve as a source of hope and support. Grace Zurielle Malolos, et al. analyze the effect of the social distancing restrictions in Philippines on church gatherings, and the need for more research on the effect of church gatherings on transmission, as well as church-state relations.

Two short communications highlight the importance of nutrition and exercise as global health factors. Alva Supit, et al show efforts to curtail bushmeat eating through church leadership in a Christian-majority region of Indonesia as one approach to fostering health in an era of pandemics and NCDs. Physiotherapist Qais Gasibat from Libya reviews the latest data on exercise as an adjunct to enhance the immunogenicity of SARS $\mathrm{CoV} 2$ and other vaccines, especially in at-risk populations.

Two surgical case reports from low-resource settings of rural India by Royson Dsouza, et al highlight the resourcefulness needed to provide good quality surgical services for liver abscess and breast cancer management.

Two poems by Professor Reena George round out this issue: Burnout which gives resurrection hope through death filled days, and Alone at Christmas showing the value of the pearl of great price.

In facing the complexities of global climate change, and its human health consequences, as well as global vulnerabilities highlighted by the current pandemic, we need now, more than ever, to look at the data, the trends, the causes, and the cures. We need to pray for the courage to critically self-evaluate, and to offer deeply transformational solutions to these issues in light of the renewal of all of groaning creation, awaiting the engagement of the children of God (Rom 8:18-30). Professor Sigve Tonstad proposes a "Theology of Ecology" to interpret Scripture anew, retrieve materiality, highlight the faithfulness of God, acquire a new vision of community, pursue sabbath rest, and to 
restore compassion and grace. ${ }^{1}$ May we all be found faithful in that pursuit.

\section{References}

1. Tonstad SK. A theology of ecology: earthcare and health. In: O'Neill DW, Snodderly E, editors. All creation groans: toward a theology of disease and global health. Eugene, OR: Pickwick; 2021. p. 60-79. 